\title{
AS MANIFESTAÇÕES BIOPOLÍTICAS NA CONFORMAÇÃO DOS ESPAÇOS CITADINOS DO PLANALTO NORTE CATARINENSE E SUAS IMPLICAÇÕES EM RELAÇÃO AO DESENVOLVIMENTO REGIONAL
}

\author{
Sandro Luiz Bazzanella* \\ Silvano Silvero da Silva**
}

\begin{abstract}
Resumo
Este artigo é resultante do projeto de pesquisa intitulado "A relação biopolítica na conformação dos espaços citadinos do Planalto Norte Catarinense e suas implicações no desenvolvimento regional”, desenvolvido entre os anos de 2013 e 2014, na Universidade do Contestado. Por meio deste projeto, buscou-se identificar as manifestações biopolíticas na conformação dos espaços citadinos das cidades de Canoinhas e Três Barras como forma de conferir efetividade à administrabilidade da vida e da morte de tais cidadãos. A partir dos pressupostos teóricos e conceituais advindos da filosofia políticojurídica do filósofo italiano Giorgio Agamben, a cidade pode se apresentar e ser analisada como paradigma político da contemporaneidade, que se expressa no campo de concentração, lugar onde se potencializa o viver e se administra o morrer.
\end{abstract}

Palavras-chave: Cidades. Biopolítica. Vida. Morte.

\footnotetext{
* Doutor em Ciências Humanas pela Universidade Federal de Santa Catarina (UFSC). Docente do Programa de Pós-Graduação Stricto Sensu em Desenvolvimento Regional da Universidade do Contestado (UnC).

Email: sandroluizbazzanella@gmail.com

** Graduando em Ciências Sociais pela Universidade do Contestado (UnC). Email: pjmpdasilva@hotmail.com
} 


\section{Introdução}

O filósofo francês Michel Foucault (1924-1984), em seus estudos sobre o Estado, o território e a população, argumenta que, na modernidade, a vida biológica foi incluída nos mecanismos e nos cálculos do poder estatal, o que transformou a política em biopolítica. Por seu turno, o filósofo italiano Giorgio Agamben (1942-...) toma como ponto de partida as reflexões de Foucault. Porém, posiciona-se de forma diferencial, concebendo a biopolítica não apenas como um fenômeno da modernidade, mas afirmando que a biopolítica se apresenta nas estruturas jurídicas e políticas, as quais orientam a civilização ocidental desde seus primórdios. Assim, desde o início da civilização ocidental, a vida foi e é reduzida a seus aspectos meramente biológicos. O corpo biológico do cidadão - destituído de direitos e transformado em vida nua - torna-se sacrificável, matável e descartável, de acordo com os interesses do poder soberano em fazer viver, ou deixar morrer.

Neste sentido, este artigo procura contribuir para identificar as manifestações biopolíticas na conformação dos espaços citadinos das cidades de Canoinhas e Três Barras. De modo geral, percebe-se que a cidade é marcada por perspectivas biopolíticas, visto que a administrabilidade do território e da população, cada vez mais, é influenciada pelo rigoroso controle e monitoramento, através de diversas formas e mecanismos de gestão da vida reduzida em seus aspectos meramente biológicos.

Em contraponto à dinâmica da polis grega, onde a vida justificava-se em seu âmbito público, nas cidades contemporâneas a vida é conduzida para preocupações e esforços individuais e privados que se limitam à produção e ao consumo de si mesma. Seguindo os parâmetros biopolíticos de Foucault e Agamben, reconhecendo e salvaguardando suas diferenças teóricas e conceituais, é possível e necessário colocar em jogo a conformação dos espaços públicos e suas variáveis biopolíticas. Essas diferenças se manifestam nas cidades na contemporaneidade. Pode-se partir do pressuposto 
de que dificilmente a cidade produzirá espaços públicos se não tiver a capacidade de olhar seus habitantes como seres humanos livres em sua politicidade, potencializados para além de sua dimensão biológica, submetida à gestão econômicoadministrativa contemporânea.

As questões que este artigo se propõe a responder são: como se organizam os espaços das cidades, em específico as cidades de Canoinhas e Três Barras, e se esses são regidos por uma perspectiva biopolítica.

Com o intuito de submeter ao debate público as reflexões decorrentes da pesquisa, o artigo foi dividido em cinco partes: $\mathrm{Na}$ primeira parte, de forma sucinta, é apresentada a questão das "Perspectivas históricas sobre o desenvolvimento das cidades aos dias atuais". A segunda parte trata de Elementos Conceituais na definição de Biopolítica." Na terceira parte, é relatado o Estudo de caso: as manifestaçôes biopoliticas na conformação dos espaços citadinos nas cidades de Canoinhas e Três Barras". A quarta parte apresenta os Métodos da pesquisa; e, na quinta parte, são feitas as Consideraçôes finais: Desenvolvimento para que e para quem?

Este estudo procura demonstrar como a cidade pode ser um espaço para potencializar a vida pública de seus habitantes, tanto quanto poderá ser um meio para administrar a vida biológica e a morte de seus cidadãos. A política pensada em sua variável biopolítica tende a gerenciar a cidade apenas como forma de manutenção da vida nua de seus cidadãos. O locus de procedimentos administrativos do território e da população conformada sobrevive desprovido de qualidade de vida, que, entre outras exigências, requer a participação dos cidadãos no âmbito das decisões públicas. Para o estudo de caso, reflexões e conceitos presentes em diversas obras de Agamben foram utilizados, entre eles: vida nua, estado de exceção e campo de concentração. Tais pressupostos conceituais auxiliarão a identificar as manifestações biopolíticas na conformação dos espaços citadinos das cidades de Canoinhas e Três Barras.

A metodologia utilizada foi a pesquisa qualitativa. Nesta perspectiva, a pesquisa cotejou aspectos do arcabouço teórico e conceitual de Michel Foucault e Giorgio 
1 Esta abordagem de "perspectivas históricas" tem a intenção de apresentar ao leitor elementos que lhe possibilitem se aproximar $\mathrm{da}$ compreensão da importância vital que as cidades possuem na conformação política, ética e estética da vida humana. Não é pretensão dos autores fazer uma historiografia das cidades.
Agamben e de autores correlatos, sobretudo em torno do conceito de biopolítica, presente em textos e reflexões que tais filósofos desenvolveram, ao longo de seu percurso investigativo, procurando compreender genealogicamente e arqueologicamente aspectos políticos, econômicos, jurídicos e institucionais que conformam o percurso civilizatório ocidental até a modernidade.

Além dos estudos teóricos, em pesquisa de campo, através de conversas informais num contexto de observação participante, durante o período de 03 meses, abordouse cidadãos transeuntes nas ruas dos centros e das periferias dos municípios de Canoinhas e Três Barras. As questões abordadas a visaram perscrutar a compreensão dos entrevistados em relação a conformações dos espaços citadinos em que circunscrevem cotidianamente suas existências, com o intuito de compreender manifestações biopolíticas em tais espaços citadinos.

\section{Perspectivas históricas sobre o desenvolvimento das cidades aos dias atuais ${ }^{1}$}

Quando se pensa a vida nas cidades e os inúmeros problemas urbanos, a maioria das pessoas parte do princípio de que, para que a população possa ter uma vida melhor no espaço urbano, faltam políticas públicas, planejamento ou segurança nas cidades. Contudo, a questão se apresenta de forma complexa. As cidades não surgem por acaso, tampouco se desenvolvem a esmo. Ainda que não se consiga entender de forma global tudo que acontece e o que envolve uma cidade, é possível partir do pressuposto que, na conformação dos espaços urbanos, sempre se apresentaram princípios orientadores para a administrabilidade do território, dos indivíduos e da população que a compõem. Tais princípios necessitam ser estudados, refletidos e debatidos para que se possa avançar na compreensão das cidades atuais, possibilitando o planejamento a partir da centralidade do humano e do cidadão. Desse modo, é essencial refletir sobre as transformações históricas, 
culturais, sociais, econômicas e filosóficas que influenciam a conformação dos espaços citadinos e, a partir dessa condição, pensar quais são as perspectivas e as possibilidades para o seu desenvolvimento.

Em um resgate histórico sobre as origens dos primeiros aglomerados urbanos, estudos apontam que as primeiras cidades surgiram há mais ou menos 8.000 a.C. para garantir a segurança e a sobrevivência de seus habitantes.

De acordo com Marcelo Lopes de Souza (2001, p. 41-44):

As cidades surgiram na chamada Revolução Agrícola, ou Revolução Neolítica (nova pedra - lithikos). A primeira cidade que se tem noticia é Jericó, que existiu 8.000 Antes de Cristo às margens do Rio Jordão, na Palestina. Depois surgiram, ÇatalHuyuk, no sul da Anatólia (atual Turquia), Harapa e MohenjoDaro no Vale do Rio Indo (atual Paquistão) e Ur - na Mesopotâmia (atual Iraque).

Assim, é possível perceber que as primeiras cidades citadas, situavam-se às margens de rios e montanhas, locais que contribuíam para a segurança e a sobrevivência da cidade. Os rios serviam para saciar a sede, e os aglomerados citadinos utilizavam-nos como via de transporte da população e auxílio na subsistência, por meio da pesca e da irrigação da agricultura. As montanhas dificultavam o ataque de povos inimigos, servindo como refúgios em caso de invasão, e cumpriam um papel estratégico na segurança das cidades. Desse modo, nota-se que a segurança e as facilidades que os rios e montanhas possibilitavam para a sobrevivência da população eram um dos principais atrativos para a instalação e desenvolvimento das primeiras cidades (SOUZA, 2001).

Coincidentemente, as cidades estudadas nesta pesquisa têm muitos traços em comum com as primeiras cidades apresentadas por Souza (2001). Canoinhas, situada no Planalto Norte Catarinense, têm seu nome e história relacionados aos rios. De acordo com registros históricos, os primeiros exploradores subiram os rios Negro, Iguaçu e, depois, o Canoinhas, formando o início da cidade às margens 
16 Revista Grifos

2 Informação de acordo com a historia oficial do município, publicado no site da prefeitura, pelo Prof. Historiador Fernando Tokarski. do rio Canoinhas, que deu origem ao nome da cidade ${ }^{2}$. Canoinhas é uma das cidades mais antigas do Planalto Norte, foi emancipada em 1939, tem uma população estimada em 54.079 habitantes, e ocupa o $20^{\circ}$ lugar no ranking estadual. De acordo com dados do Instituto Brasileiro de Geografia e Estatística, o Índice de Desenvolvimento Humano (IDH) é de 0,759 (79a no ranking estadual) e a taxa de urbanização é de 75\% (IBGE, 2010).

Três Barras, por sua vez, tem sua história iniciada em 1850, quando José Teixeira Cordeiro e Lucas Cordeiro receberam extensas faixas de terra na região. Por volta de 1893, Benvindo Pacheco, juntamente com outras pessoas, instalouse na região de propriedade de José Cordeiro. A transformação da região ocorreu a partir da construção da Estrada de Ferro São Paulo-Rio Grande do Sul e da instalação da empresa madeireira Southern Brazil Lumber And Colonization Company. A região foi emancipada e elevada à condição de município em 1961. A população é estimada em 18.843 habitantes (65a no ranking estadual). $\mathrm{O}$ nome da cidade origina-se por estar situada entre as barras de três rios: rio Canoinhas, rio Negro e rio São João. O IDH é de 0, 706 (215 a no ranking estadual).

Portanto, assim como as primeiras cidades buscavam situar-se entre as margens de rios e encostas de montanhas para facilitar a segurança, a pesca, o transporte e a subsistência por meio da agricultura, as cidades catarinenses estudadas neste projeto (Canoinhas e Três Barras) seguem o mesmo padrão histórico. Na medida em que os aglomerados humanos - preocupados com a subsistência básica garantida através da caça, pesca e cultivos agrícolas - foram se desenvolvendo, começou o processo de urbanização e novas preocupações relativas à vida na cidade passaram a pautar a vida dos homens na coletividade.

Desse modo, para um primeiro esforço de conceituação sobre as cidades, buscaram-se, em Garcias e Bernardi (2008, p. 4), as origens dos termos: Civitas, Urbe e Polis, que nos permitem uma aproximação dos significados das palavras que definem o espaço urbano, ou seja, a cidade. 
O termo cidade vem do latim, civitas, que dá origem, entre outras, a palavras como cidadania, cidadão, civismo. Também latina é a palavra urbe. É hoje um sinônimo de cidade, que por sua vez, gerou termos relacionados à vida em coletividade como urbanismo, urbano, urbanidade. Unindo-se ao termo grego polis, ou seja, a cidade-estado, autônoma, independente, civil, público, o local onde a vida cívica acontece, o mercado, o ambiente político, do exercício da cidadania, chega-se a origem destes termos que definem o ambiente urbano.

Para além de questões locais, deve-se salientar que o sociólogo e urbanista Robert Park argumenta, que a cidade é fruto do esforço e do trabalho humano. O homem procura construir o mundo à sua maneira; logo a "[...] cidade é a tentativa mais bem-sucedida do homem de refazer o mundo de acordo com os desejos do seu coração. Mas, se a cidade é o mundo em que o homem criou, é também o mundo onde ele está condenado a viver daqui para frente" (PARK, 1967 apud HARVEY, 2013, p. 41).

Desde a época da polis grega, discute-se: O que é a cidade? Quem tem direito a ser cidadão? Como deve ser organizada uma cidade? Aristóteles, no livro " $A$ Política", defende que é na cidade que se busca o viver bem. Para o filósofo estagirita, a cidade não era apenas um espaço para viver juntos, mas para viver bem juntos. Aristóteles afirma que: "[...] toda cidade é uma espécie de comunidade, e toda comunidade se forma com vista a algum bem". (ARISTÓTELES, 1989, p. 12) E isso apenas seria concretizado se o cidadão fosse um parceiro da comunidade, se participasse ativamente dos debates e das decisões sobre as questões que envolvessem a vida pública da cidade. Sob bases aristotélicas, pode-se colocar em jogo até que ponto os moradores de Canoinhas e Três Barras participam da vida pública e se envolvem na construção dos espaços citadinos.

Nesse sentido, pensar a cidade significa pensar a própria vida do homem na coletividade. Mais do que comentar sobre a delimitação do espaço geográfico urbano, a descrição da arquitetura dos prédios, casas, ruas, ou ainda, mais do que 
tratar sobre as coisas visíveis da cidade, é preciso que sejam discutidas as ideias que a orientam. Pois, as cidades podem ser vistas como mediadoras de relações humanas, potencializando ou diminuindo a vida em seu âmbito público. Para Garcias e Bernardi (2008, p. 14):

A cidade constitui-se no ambiente que possibilitou ao homem intensificar seus relacionamentos, tornando-os mais complexos e intensos e, provavelmente, assim acelerar o processo de evolução [...]. Para ser justa, a cidade deve garantir e assegurar direitos e obrigações a todos independentemente de onde se encontrem no espaço urbano ou na estrutura da sociedade.

Sob tais pressupostos, percebe-se que a cidade e as formas de vida que nela se constituem foram temas de variados objetos de pesquisa para pensadores que se preocuparam com as relações e a convivência do homem na vida em sociedade. Entre as várias reflexões, pode-se entender a cidade como um lugar para a socialização do ser humano. Espaço em que o homem aprende a relacionar-se, interagir, dialogar e conviver em sociedade. Ou dito de outra forma: a cidade pode ser o meio a partir do qual o ser humano constrói a sua humanidade. E pode ser vista, ainda, como um lugar para o aprisionamento do homem; afinal, na vida em sociedade, o ser humano conforma-se a um conjunto de regras, valores, leis, costumes, que, pela coerção social, ele deve seguir. Pode-se, também, compreender a cidade como o espaço onde o ser humano deve limitar-se a viver dentro dos pactos estabelecidos para a convivência coletiva. E é nesse meio que sua vida vai sendo construída, moldada, circunscrita e/ou potencializada.

\section{Aspectos conceituais em torno da biopolítica}

Para muitos, a política na atualidade está relacionada aos partidos, aos governantes e à corrupção. Algo distante da vida das pessoas. E no senso comum, a maioria procura se afastar dessa ligação, com certo desprezo pela política. 
Poucos vinculam a política como condição inerente à vida em sua totalidade. No entanto, é preciso refletir: qual a relação existente entre política e vida? De que forma essa relação influencia a convivência nas cidades e na sociedade de forma em geral?

Ao lançar um olhar sobre os gregos antigos, constata-se que eles não tinham apenas um conceito de vida. Para eles, a vida era definida a partir de duas perspectivas distintas: a Zoé, que representava os aspectos biológicos, a corporeidade, substrato para a manifestação e manutenção da vida, intimamente vinculada ao reino da necessidade, ou seja, a zoé vinculava-se a oikonomia, a casa, ao espaço das sombras, como locus por excelência da sobrevivência ou manutenção do corpo. A outra forma de conceber, ou definir a vida era a bios, que representava a vida qualificada em seu âmbito público, partícipe da vida pública.

A vida em sua dimensão biológica, privada, pouco importava para os gregos. Para eles, o importante era a vida pública, vida que se manifestava publicamente na construção do sentido e na finalidade da vida humana em sua condição essencialmente política. Os gregos foram os primeiros a pensar a vida na polis (cidades-estados), ou seja, a vida potencializada no espaço público. Como política e vida se relacionavam, a cidade era o meio para essa potencialização.

Foi o filósofo francês Michel Foucault quem conferiu a articulação conceitual ao termo biopolítica em suas articulações arqueológicas e genealógicas na década de 1970 do século XX. Foi no período de 1974 a 1979 que o termo ganhou a centralidade nas pesquisas, nas obras e entrevistas do filósofo, imprimindo-lhe uma complexa interpretação, articulando as esferas biológicas, históricas, políticas, epistemológicas e ontológicas, sobre as quais se desenvolveram as relações de saber e de poder na modernidade, e em cuja centralidade se apresenta a vida. É a partir dessa ressignificação conferida pelo filósofo francês ao termo biopolítica que, em nossos dias, entre vários autores e linhas de estudo e pesquisa, surgiu uma chave de leitura da realidade social e política contemporânea. 
Para Foucault (1926-1984), é a partir do século XVIII que a vida se tornou - de maneira mais explícita - a centralidade das preocupações políticas. A vida apreendida em sua biologicidade tornou-se alvo de procedimentos político-administrativos. Logo, devem-se implementar processos de gestão sobre o corpo dos indivíduos, promovendo condições de higiene e saúde individual, garantindo a vida da população. A dimensão política passou a justificar-se no cuidado com a vida, com o corpo do indivíduo, que é condição do cuidado com a espécie humana, com a população e a garantia de manutenção do território.

Foucault (1999) argumenta que, na modernidade, houve uma mudança de paradigma em relação ao poder soberano. Se antes o governante (soberano) tinha o direito de matar seus súditos, ou deixá-los viver, na modernidade o poder soberano vai decidir entre os que devem viver e os que são deixados para morrer. Ou seja, ocorreu uma mudança, redefinindo o poder do soberano. $\mathrm{O}$ autor comenta que

[...] uma das maciças transformações do direito político do século XIX consistiu, não digo exatamente em substituir, mas em completar esse velho direito de soberania - fazer morrer ou deixar viver - com outro direito novo, que não vai apagar o primeiro, mas vai penetrá-lo, perpassá-lo, modificá-lo, e que vai ser um direito, ou melhor, um poder exatamente inverso: poder de "fazer" viver e de "deixar" morrer. O direito de soberania é, portanto, o de fazer morrer ou de deixar viver. $\mathrm{E}$ depois, este novo direito é que se instala: o direito de fazer viver e de deixar morrer. (FOUCAULT, 1999, p. 287).

O direito de fazer viver ou deixar morrer parece ser o regulamento oculto da administrabilidade de um território e de sua população, e essa condição se manifesta, se fizermos uma análise dos recursos financeiros que são destinados para uma parte do território (centro, bairros, localidades) em detrimento de outros. $\mathrm{Ou}$, ainda, recursos são investidos para que uma parte da população tenha melhores condições de 
vida, em muitos casos, em detrimento de outra parte que fica desassistida. Assim, o que se apresenta de forma inequívoca é a relação entre custo e benefício na administrabilidade da vida e da morte dos cidadãos. Verificam-se, nessas questões, alguns fundamentos ocultos da biopolítica e que Foucault vai chamar de governamentabilidade.

Por esta palavra, "governamentalidade", entendo o conjunto constituído pelas instituições, os procedimentos, as análises e reflexões, os cálculos e as táticas que permitem exercer essa forma bem específica, embora muito complexa, de poder que tem por alvo principal a população, por principal forma de saber a economia política e por instrumento técnico essencial os dispositivos de segurança. Em segundo lugar, por "governamentalidade" entendo a tendência, a linha de força que, em todo o Ocidente, não parou de conduzir, e desde há muito, para preeminência, desse tipo de poder que podemos chamar de "governo" sobre todos os outros - soberania, disciplina - e que trouxe, por um lado, o desenvolvimento de toda uma série de aparelhos específicos de governo [e, por outro lado], o desenvolvimento de toda uma série de saberes. Enfim, por "governamentalidade", creio que se deveria entender o processo, ou antes, o resultado do processo pelo qual o Estado de justiça da Idade Média, que nos séculos XV e XVI se tornou o Estado administrativo, viu-se pouco a pouco "governamentalizado". (FOUCAULT, 2008, 143-144).

Desse modo, o filosofo francês vai descrevendo a mudança de paradigma do poder soberano na modernidade. A riqueza de uma nação está nos recursos disponíveis em seu território. E, entre os recursos do território, a vida e a segurança da população assumem lugar privilegiado nos cálculos dos poderes e dos saberes de que dispõem e desenvolvem para a administrabilidade dos indivíduos, da população e do território. É a partir dessas perspectivas de uma razão governamental da população e do território que Foucault (2008) estabelece os pressupostos da biopolítica na modernidade.

$\mathrm{Na}$ esteira das reflexões biopolíticas de Foucault, mas diferenciando-se em aspectos cruciais da análise foucaultiana, 
o filósofo italiano Giorgio Agamben parte do pressuposto de que a biopolítica não é um fenômeno moderno, mas um fenômeno que se apresenta na gênese da civilização ocidental, em sua estrutura política e jurídica desde a Antiguidade clássica greco-romana. Portanto, desde os primórdios da civilização ocidental, a vida estaria na centralidade da dinâmica política como busca do bem viver.

Ainda na perspectiva agambeniana, a biopolítica revela-se contundente na modernidade, manifestando-se por meio do poder soberano, que tem o direito de fazer viver e de matar. O poder soberano ao estabelecer o estado de exceção como regra, em que a vida é destituída de seus direitos e de sua cidadania, transformando-se em vida nua e, como tal, sacrificável de acordo com os interesses do poder soberano na manutenção da ordem. A vida assumida pela política moderna é a vida meramente biológica,

[...] aquilo que caracteriza a política moderna não é tanto a inclusão da zoè na polis, em si antiqüíssima [sic], nem simplesmente o fato de que a vida como tal venha a ser um objeto eminente dos cálculos e das previsões do poder estatal; decisivo é, sobretudo, o fato de que, lado a lado com o processo pelo qual a exceção se torna em todos os lugares a regra, o espaço da vida nua, situado originariamente à margem do ordenamento, vem progressivamente a coincidir com o espaço político, e exclusão e inclusão, externo e interno, bios e zoè, direito e fato entram em uma zona de irredutível indistinção [...]. O que está em questão é a vida nua do cidadão, o novo corpo biopolítico da humanidade. (AGAMBEN, 2002, p. 16-17).

$\mathrm{O}$ posicionamento analítico de Agamben frente às formas de vida que se constituem politicamente no Ocidente coloca nossa capacidade reflexiva e analítica diante de uma realidade paradoxal. Por um lado, a vida reduzida em sua condição biológica torna-se vida nua, destituída de direitos, de cidadania, à mercê dos mais variados jogos de interesses do poder soberano. Por outro lado, proliferam os discursos e as políticas públicas provenientes da razão de Estado em 
defesa da vida, em garantias de segurança e, sobretudo, na potencialização da qualidade de vida dos indivíduos, seja no cuidado com a saúde, seja no acesso aos bens de consumo.

Nessa perspectiva, Agamben fala de um biopoder contemporâneo que reduz a vida à sobrevida biológica, de um biopoder que produz sobreviventes confinados em prisões localizadas em territórios blindados em relação aos direitos humanos, como a base de Guantánamo mantida pelos EUA em território cubano, ou a territórios desprovidos de interesses estratégicos na reprodução da lógica do capital. Nessa direção, o filósofo italiano aponta para o aumento das câmeras de vigilância em nossos prédios, em ruas e praças, dos controles digitais a que estamos submetidos pelos sistemas de vigilância em nome da segurança nacional.

A partir das interpretações de Foucault e de Agamben, evidencia-se a biopolítica como manifestação civilizatória moderna da centralidade da vida biológica. No âmbito das perspectivas civilizatórias que se apresentam na modernidade, pode-se afirmar que a biopolítica decorre de significativas alterações na cosmovisão que se alicerça em prerrogativas ontológicas, epistemológicas, éticas e políticas, manifestandose e estratégias de cientifização da vida e da morte, que contribuem para a verificação e o controle das estatísticas em relação aos custos de fazer viver e deixar morrer.

Portanto, partindo do pressuposto de Agamben - de que a biopolítica se apresenta em toda sua intensidade na contemporaneidade, no fato de que o campo de concentração é o paradigma do nosso tempo -, o que se apresenta em toda sua intensidade e urgência é compreender como se constitui o espaço geográfico da cidade, como forma de administrabilidade da vida dos indivíduos em sua condição biológica, ou seja, entender como a conformação dos espaços da cidade conforma a vida biológica dos cidadãos.

Ao relacionar o conceito de biopolítica e sua incidência na organização vital das cidades, Agamben recorre ao filósofo estagiriata, Aristóteles, mais especificamente ao seu livro A Politica, e destaca a seguinte passagem: 
Não é um acaso, então, que um trecho da Política situe o lugar próprio da polis na passagem da voz à linguagem. $\mathrm{O}$ nexo entre vida nua e política é o mesmo que a definição metafisica do homem como "vivente que possui linguagem" busca na articulação entre fhoné e logos. A pergunta: "de que modo o vivente possui linguagem?" Corresponde exatamente àquela outra: "de que modo a vida nua habita a polis?" (AGAMBEN, 2002, p. 15).

Desse modo, Agamben relaciona a polis como o espaço por excelência da voz, da linguagem, da fala ao homem que deve viver, tanto quanto pode ser, ao mesmo tempo, um lugar para aqueles que são deixados para morrer. Para o filósofo italiano, aquilo que chamamos de cidade apresenta-se como um determinado território, habitado por uma determinada população governada pelo poder soberano sob pressupostos políticos, administrativos e jurídicos, assentados no permanente estado de exceção. A racionalidade político-administrativa jurídica de Estado no governo da cidade conforma espaços, constrói ruas, casas, prédios e organiza o espaço geográfico, procurando abarcar a totalidade das relações e da vida humana em suas dimensões produtiva, de lazer, de educação, de saúde e de segurança.

Assim, pode-se pressupor que, quanto mais intensa e efetiva a administrabilidade dos espaços da cidade, melhores as condições de acomodação e conformação da vida biológica das pessoas. Isso contribui para o aumento dos níveis de produtividade e consumo de uma determinada cidade, bem como de toda uma região.

Portanto, o que está em jogo é compreender a dinâmica biopolítica que rege a organização de nossas cidades, na distribuição e conformação dos espaços geográficos da cidade em que tipos humanos podem transitar, ou mesmo em que espaços, em que lugares, parte dos moradores deve ficar circunscrita como forma de conferir efetividade à administrabilidade da vida e da morte de tais cidadãos. 
Estudo de caso: as manifestações biopolíticas na conformação dos espaços citadinos das cidades de Canoinhas e Três Barras

A partir das teorias analisadas, pode-se afirmar que a organização dos espaços urbanos das cidades de Três Barras e de Canoinhas é regida por uma perspectiva biopolítica. A partir dos parâmetros biopolíticos presentes nas reflexões de Giorgio Agamben, a cidade pode se apresentar como paradigma do campo de concentração, lugar para fazer viver ou para se administrar a morte. Mas, em outra perspectiva, pode ser pensada e, talvez urge concebê-la como ágora pública, em que as questões da cidade podem ser debatidas livre e abertamente entre os cidadãos.

Para ilustrar suas reflexões sobre o conceito de vida nua, Agamben recorre a uma figura do direito romano arcaico, chamado "Homo Sacer". Este era um indivíduo dado como morto, embora ainda estivesse vivo. Depois de cometer algum delito, sua condenação era à exclusão da civitas dentro da própria cidade. $\mathrm{O}$ homo sacer vivia aos arredores da cidade, mas não podia ter o convívio com os outros. Perdia o valor da vida em seu âmbito público. Carregava em si apenas uma estrutura biológica, que não o identificava como um animal; porém, o homo sacer não era mais reconhecido como ser humano. Abandonado a própria sorte, poderia ser morto por qualquer pessoa em qualquer lugar sem que isso caracterizasse delito e consequências para quem o sacrificasse (AGAMBEM, 2002)

A vida do homo sacer era completamente destituída de direitos, de valor, de proteção. Era uma vida nua, sacrificável, matável, descartável. Embora essa figura tenha desaparecido do direito romano, na atualidade, conforme a perspectiva de Agamben, "todos somos homo sacer", uma vez que toda a estrutura político-jurídica em que estamos inseridos não garante efetivamente direitos em situações de exceção, expondo-nos ao abandono, à morte em situações de anomia. No estudo da conformação dos espaços citadinos, percebe-se que, no caso das periferias das cidades, parte de sua população 
é condenada a viver na condição de homo sacer. Ou seja, nas periferias há moradores incluídos e excluídos da cidade na sua condição de vida nua, destituída dos plenos direitos, exposta diuturnamente à violência. Retomando a argumentação de Foucault e aprofundando-se em suas reflexões, presentes na obra Microfísica do poder, o filósofo fala que a população é julgada e obrigada a viver de acordo com algumas classificações. "Somos julgados, condenados, classificados, obrigados a desempenhar tarefas e destinados a certo modo de viver ou morrer em função dos discursos verdadeiros que trazem consigo efeitos específicos de poder" (FOUCAULT, 2001, p. 180).

Nesse sentido, a partir da análise de dados das pesquisas advindos de moradores das áreas centrais e periféricas das cidades de Canoinhas e Três Barras constatam-se diversos discursos sobre as diferentes áreas da cidade que reforçam um discurso biopolítico, a divisão entre as regiões e seus habitantes. Para alguns, em determinadas regiões apenas moram ladrões, bandidos, vagabundos, pessoas sem valor, os quais, na variável biopolítica de Agamben, seriam os homo sacer dos dias atuais. Vidas meramente biológicas que poderiam ser sacrificáveis, matáveis e condenáveis, sem causar comoção, ou falta, para os demais habitantes da cidade - estes de regiões nobres e, por isso, com "mais direitos". Esse tipo de discurso vem acompanhado de preconceito e deixa como legado para a população dessas regiões condenadas, as piores moradias, as piores estradas, os piores empregos e os piores salários.

Assim como o homo sacer, muitos habitantes das cidades são rotulados como vidas sem valor, que podem ser expostas às mais diferentes formas de violência. São pessoas que podem ser abordadas com truculência pela polícia ou, ainda, presas apenas por serem consideradas de perfil pré-condenado como suspeitas. Sem o direito de ir e vir e de usufruir livremente da cidade, o homo sacer fica cada vez mais "preso a céu aberto" em áreas periféricas da cidade. E, cada vez mais, o endereço se torna um mecanismo de inclusão e exclusão nas cidades. 
O habitante periférico é destinado a viver limitado e, é deixado para morrer em áreas abandonadas da cidade.

Seguindo as reflexões na ordem da biopolítica de Foucault e Agamben, considerando suas diferenças conceituais, afirma-se que a política na atualidade reduz a vida dos indivíduos a sua dimensão biológica, e sobre a mesma, o Estado faz cálculos e organiza mecanismos para administrar aqueles que devem fazer viver e outros que serão deixados para morrer. Nesse sentido, a cidade se apresenta como manifestação hodierna dos campos de concentração, onde a vida nua era objeto por excelência das decisões políticas do poder soberano, operando em constante estado de exceção, decidindo quem viveria e quem morreria. Segundo Agamben (2002, p. 16):

O estado de exceção, no qual a vida nua era, ao mesmo tempo, excluída e capturada pelo ordenamento, constituía, na verdade, em seu apartamento, o fundamento oculto sobre o qual repousava o inteiro sistema político; a vida nua que o habitava libera-se na cidade e torna-se simultaneamente o sujeito e o objeto do ordenamento politico e de seus conflitos, o ponto comum tanto da organização do poder estatal quanto da emancipação dele.

$\mathrm{Na}$ perspectiva analítica de Agamben, os cidadãos estão diretamente vinculados ao poder soberano do Estado e é o mesmo quem pode conceder a cidadania aos seus habitantes, tanto quanto pode excluí-los desses direitos a qualquer momento. Nesse sentido, no estado de exceção, a vida nua é capturada e excluída, está dentro e fora da lei ao mesmo tempo. A vida administrada em um estado de exceção perde totalmente a sua proteção e, a qualquer momento, pode sofrer sanções, restrições e ser exterminada. Segundo o filósofo italiano: "A vida sob uma lei que vigora sem significar assemelha-se à vida no estado de exceção, na qual o gesto mais inocente ou o menor esquecimento podem ter consequências mais extremas" (AGAMBEN, 2002, p. 58). 
A consequência para parte dos indivíduos que vive nas cidades em estado de exceção é saber que, embora existam muitas leis em defesa da vida, tal ordenamento jurídico não lhes confere plenas garantias de que eles continuarão vivos. A vida nua é a todo momento monitorada, encarcerada, sacrificada. A cidade como campo de concentração, que opera sob a égide do estado de exceção limita a circulação de seus habitantes, predefine os que estão dentro e os que estão fora da lei, os que poderão viver e os que serão deixados para morrer. Criam-se áreas de suspensão de direitos, de exclusão dos indivíduos da cidade, embora territorialmente e juridicamente a cidade ainda seja uma coisa só.

Nas reflexões agambenianas relativas aos campos de concentração, como paradigma biopolítico contemporâneo, talvez a diferença das cidades atuais, com os campos esteja na visibilidade e intensidade das políticas de controle e manipulação da vida. Nos regimes totalitários, eram bem definidos os espaços/campos e a população que deveria ser vigiada, cercada e levada para as câmaras/máquinas da morte. A guerra era aberta e todos sabiam, e, se não sabiam, era porque

3 Mas não se pode esquecer de que as experiências totalitárias da primeira metade do século $\mathrm{XX}$ (nazismo, fascismo e stalinismo) surgiram e se constituíram no bojo das democracias liberais vigentes naquele contexto. não queriam saber que parte da população indesejada seria condenada, sacrificada ${ }^{3}$. Já nas democracias contemporâneas nas quais estamos inseridos, passa-se a ideia de que todos os lugares e todos os habitantes são formados por cidadãos livres, que têm os mesmos direitos, e podem exercer sua cidadania em condições de igualdade.

Contudo, na prática observa-se que a vigilância, o controle e a violência dos campos de concentração podem ser facilmente constatados nas periferias das cidades. Embora isso ainda apareça de forma obscura, para Agamben (2002, p. 171): "O campo como localização deslocante é a matriz oculta da política em que ainda vivemos, que devemos aprender a reconhecer através de todas as suas metamorfoses [...]".

As metamorfoses do campo de concentração podem ser encontradas nas arquiteturas das periferias, na forma 
como são tratados os seus habitantes, nas abordagens policiais, nas condições de trabalho, nas condições de moradia, no saneamento básico, nas perspectivas de vida. Sob tais pressupostos e com suas especificidades, as cidades revelam de uma forma ou de outra, diversas facetas da biopolítica.

Durante o desenvolvimento da pesquisa, constatouse que as cidades de Canoinhas e Três Barras apresentam características de ágora pública em algumas áreas e de campo de concentração em outras. Circulando de uma área para outra, não parece que a cidade é a mesma. Alguns contrastes na conformação dos espaços citadinos em Canoinhas podem ser visualizados nas imagens que ilustram as diferenças na urbanização, pavimentação, saneamento básico, moradia, iluminação, dentro da mesma cidade.

Essas situações podem ser constatadas nas imagens $\left(\right.$ fotos $\left.^{4}\right)$ a seguir:

Figura 1 - Rua Projetada, no Campo da Água Verde, na periferia de Canoinhas.

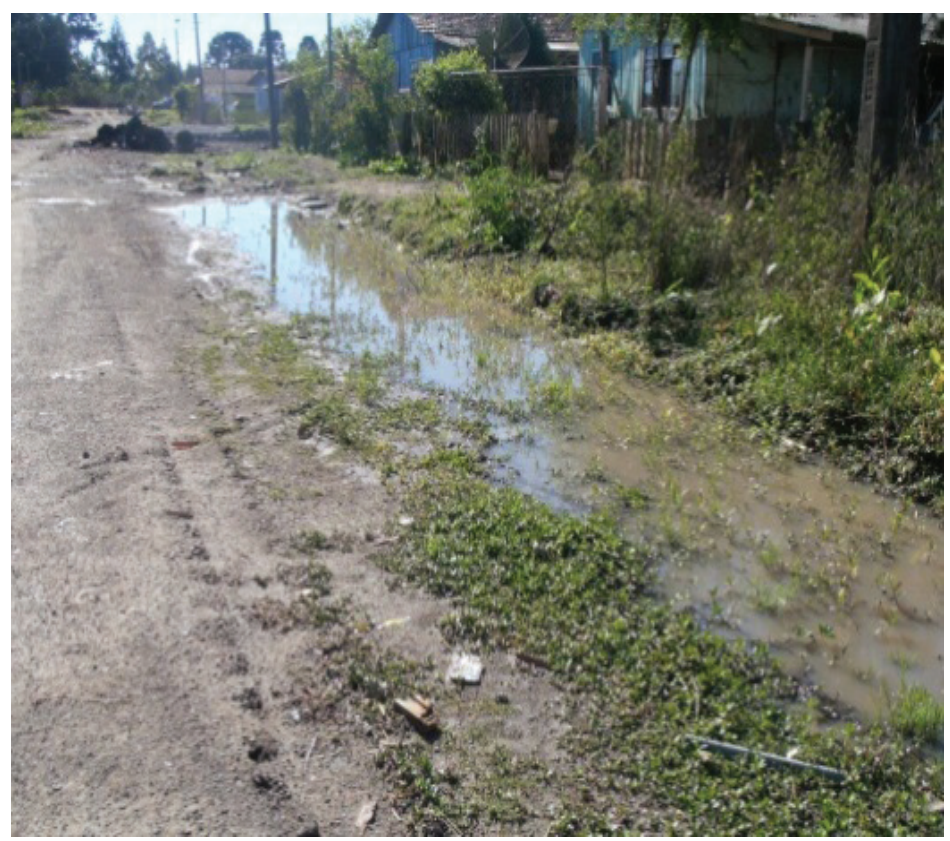

4 As fotos que compõe este artigo pertencem ao acervo de imagens dos autores da pesquisa e deste artigo. 
Figura 2 - Rua Basílio Humenhuk, no Bairro Sossego, na área central de Canoinhas.

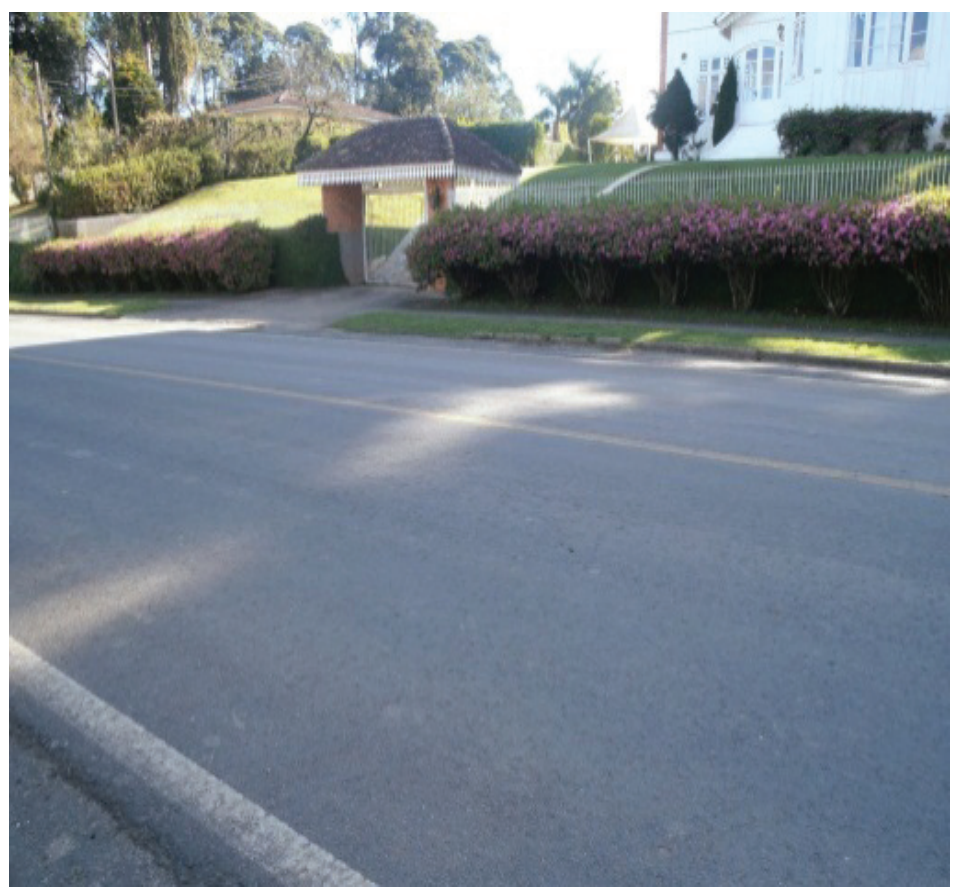

As imagens, a estética e a conformação dos espaços citadinos são bem diferentes entre as regiões que compõem o espaço urbano da mesma cidade. Em Canoinhas, por exemplo, se alguém visitar o "bairro Sossego, (conhecido como bairro das mansões)" e, depoi,s a chamada "Raia" no Campo da Água Verde, a impressão que se tem é que são duas cidades completamente diferentes. No mesmo sentido, em Três Barras, visitar a "Vila Rigesa" e, em seguida, a "Charqueada" dará a impressão que as duas regiões não fazem parte da mesma cidade. São muitos contrastes sociais, embora as cidades sejam de pequeno porte, as diferenças são visíveis entre uma região e outra.

As visões presentes nos discursos dos sujeitos participantes da pesquisa sobre as cidades são diversas. Dependendo da região e da realidade em que os cidadãos estão, as perspectivas mudam completamente. Ao questionar qual é a imagem que cada cidadão tem de sua cidade, constata-se 
que os habitantes não conseguem perceber a cidade como um todo. De forma geral, limitam-se apenas à parte da cidade na qual estão circunscritos, circulam e que demarca o cotidiano ao seu redor. A partir dessas perspectivas, pode-se perguntar: A cidade é concebida como uma totalidade? As políticas, as perspectivas, o desenvolvimento são voltados para todos? Mesmo no caso estudado em que os municípios são de pequeno porte, parece que a cidade não é o mesmo território onde todos se identificam.

Analisando as diferentes regiões e como cada parcela da população vive a vida no território, percebem-se diferenças e perspectivas na mesma cidade. Para Zygmunt Bauman (2001), cada habitante pode ter um mapa mental diferente da mesma cidade. Em seu livro Modernidade Líquida, o sociólogo polonês descreve como a cidade é percebida de acordo com a experiência de vida de cada habitante.

A cidade, como outras cidades, tem muitos habitantes, cada um com um mapa da cidade em sua cabeça. Cada mapa tem seus espaços vazios, ainda que em mapas diferentes eles se localizem em lugares diferentes. Os mapas que orientam os movimentos das várias categorias de habitantes não superpõe, mas, para que qualquer mapa "faça sentido", algumas áreas da cidade devem permanecer sem sentido. Excluir tais lugares permite que o resto brilhe e se encha de significado. (BAUMAN, 2001, p. 121).

A partir das premissas apresentadas por Bauman, alguns cidadãos foram indagados sobre certos endereços e, qual a opinião deles sobre alguns lugares da cidade. Fica evidente como parte da população vive circunscrita em áreas restritas da cidade. Parece que partes da cidade são invisíveis para seus olhos. Alguns moradores, de acordo com a pesquisa realizada, mesmo não conhecendo ou não frequentando determinadas regiões da cidade, já possuem uma imagem estereotipada das mesmas, o que os impede de transitar livremente nessas áreas.

De forma geral, percebe-se que as cidades estão divididas em áreas onde parte da população vive sem se relacionar com 
os habitantes que residem em áreas diferentes da cidade. Para certos moradores, pisar em outro bairro é como pisar em um campo inimigo, minado e que está preparado para causar algum tipo de violência ou danos; assim, prejuízos podem ser evitados com um afastamento desses locais e, consequentemente, dos moradores de certas áreas.

Outra questão que marca as diferenças nas cidades relaciona-se com a segurança ou ameaça que representa segmentos dessa população. Para manter a vigilância e o controle de algumas áreas e segmentos da sociedade, a cada dia instalam-se mais câmeras de vigilância, muros altos, cercas elétricas, arames farpados, rondas policiais - instrumentos de controle utilizados nos campos de concentração e nas prisões, e que atualmente se tornam parte integrante da paisagem urbana.

Figura 3 - Esquina da Rua Roberto Elke, na área central de Canoinhas.

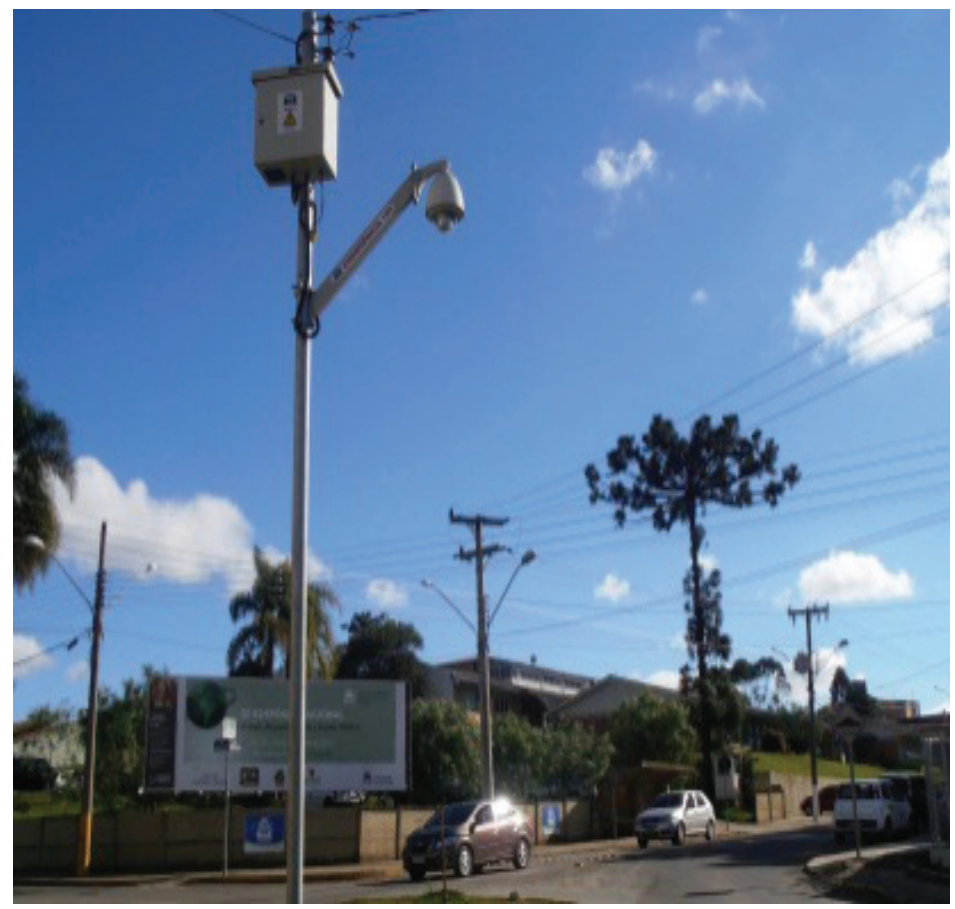


Figura 4 - Avenida Expedicionários, no Bairro Campo da Água

Verde, em Canoinhas.

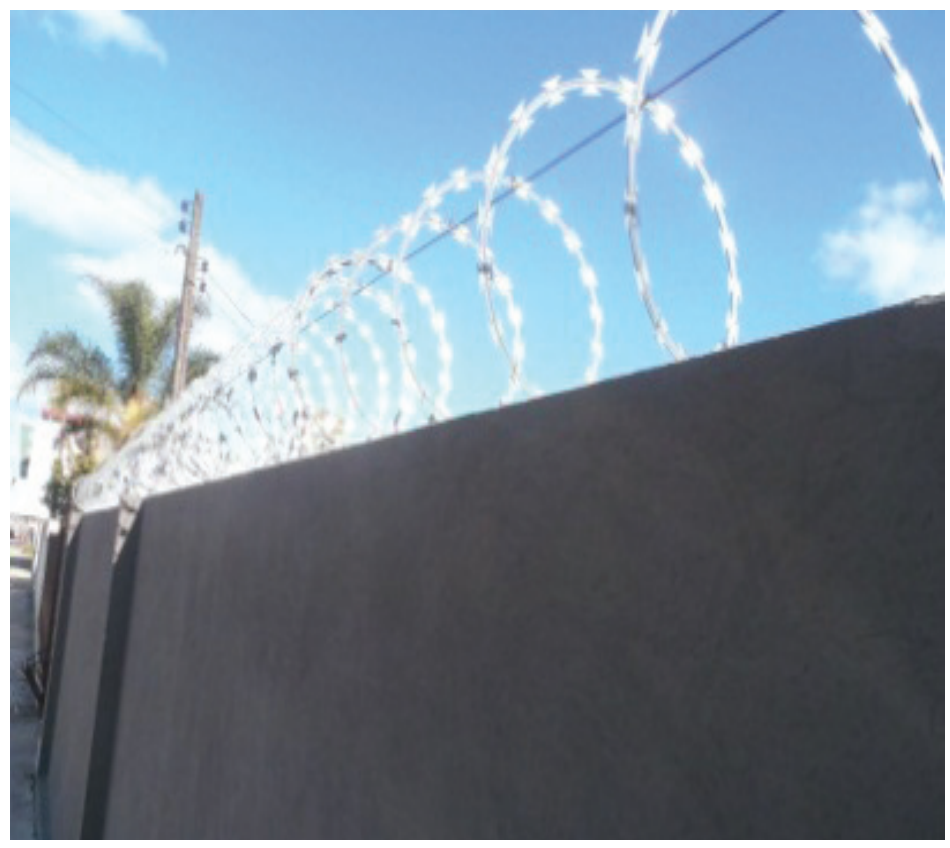

Figura 5 - Rua Curitibanos, na área central de Canoinhas.

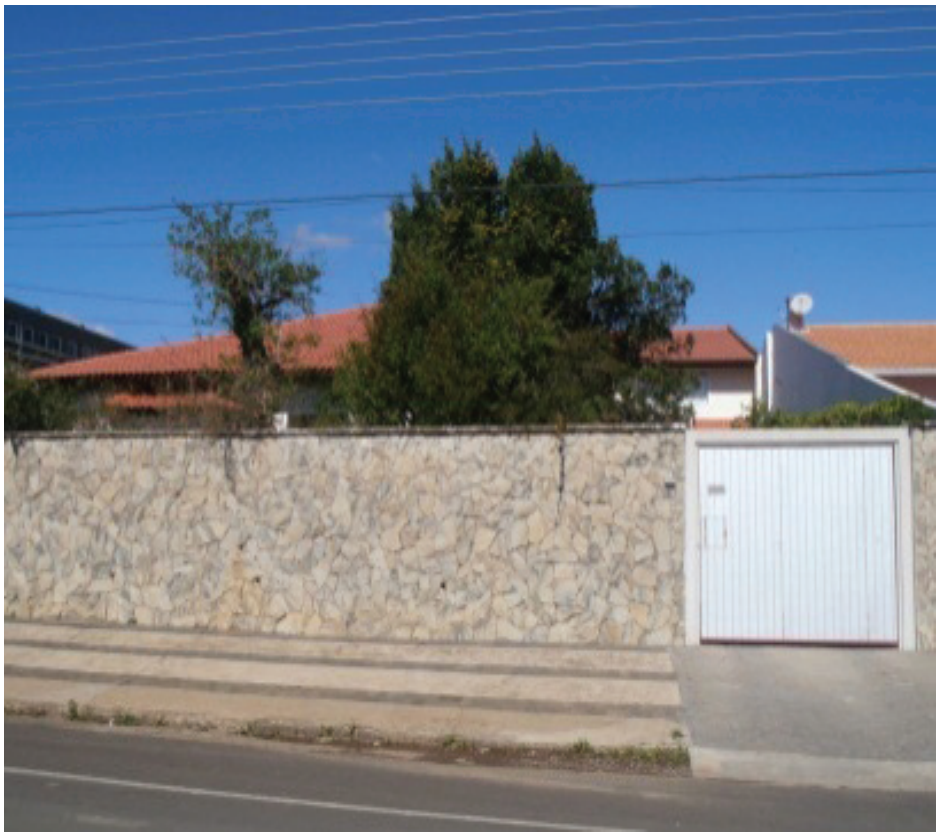


A partir do discurso do medo, reverberado pelos pesquisados, medinte frases como: "Lá é o Iraque brasileiro", "tenho medo de ir lá e ser assaltado", "naquela região, é perigoso ir por conta dos bandidos que moram lá", "jamais moraria em uma região tão perigosa como aquela", parece que as cidades são muito violentas e que isso é fruto de partes da população que habitam determinadas áreas menos privilegiadas. Porém, ao analisar alguns dados de ocorrência policial, verifica-se que parte desse discurso não se sustenta. Segundo Relatório de Crimes ocorridos em Três Barras e em Canoinhas no período de janeiro de 2013 a agosto de 2014, a situação assim se apresenta:

Tabela 1 - Relatório de crimes ocorridos em Canoinhas e Três Barras (jan. 2013/ago. 2014)

\begin{tabular}{llll}
\hline Crime & \multicolumn{2}{l}{ Três Barras } & Canoinhas \\
\hline Homicídios & $2013=4 ;$ & $2014=1$ & $2013=1 ; 2014=3$ \\
Tentativas de Homicídio & $2013=6 ;$ & $2014=4$ & $2013=6 ; 2014=1$ \\
$\begin{array}{l}\text { Roubo: Pessoa, comércio } \\
\text { e residência }\end{array}$ & $2013=9 ;$ & $2014=6$ & $2013=15 ; 2014=11$ \\
\hline
\end{tabular}

Fonte: $3^{\circ}$ Batalhão de Policia Militar (2013-2014).

A partir dos dados apresentados na Tabela 1, coletados junto ao $3^{\circ}$ Batalhão de Policia Militar - sediado no município de Canoinhas/SC e responsável pela política e pelas estratégias de segurança dos municípios de Canoinhas e Três Barras, considera-se que não haveria justificativa para alarme. Então, os discursos do medo e do perigo que determinados bairros, regiões e segmentos da população representariam na região pesquisada seriam sem fundamento. Porém, como explicar as constantes rondas policiais, quase sempre nos mesmos endereços? Por que é escolhido um endereço e não outro para fazer ronda policial? A escolha das áreas da cidade em que ocorre ronda policial e os tipos de pessoas que são consideradas suspeitas são resultantes das perspectivas biopolíticas? É possível relacionar o biotipo com a biopolítica? 
Visitando a Unidade Prisional Avançada em Canoinhas, constata-se que a maioria dos encarcerados são moradores dos mesmos bairros, e possuem os mesmos biotipos. Será que as pessoas que desrespeitam as leis são todas moradoras da mesma região? Ou será que, nas cidades, a biopolítica é o fundamento para decidir quais pessoas serão selecionadas, controladas, aprisionadas (como os campos de concentração) e separadas daqueles que poderão viver livremente? $\mathrm{O}$ discurso de combate às drogas e à violência não seria uma variável biopolítica para manter o controle sobre a cidade e seus habitantes?

Para parte da população, parece que a cidade não foi feita para ser usufruída e nela se viver tranquilamente. A segurança e a garantia de sobrevivência para todos os habitantes, que foi alicerce para o início das primeiras cidades, foi abandonada e limitada para alguns moradores em detrimento de outros. A confiança presente nas primeiras cidades transformouse em medo na atualidade, como bem destacou o sociólogo polonês, Bauman (2009, p. 40):

Paradoxalmente, as cidades que na origem foram construídas para dar segurança a todos os seus habitantes, hoje estão cada vez mais associadas ao perigo [...]. A arquitetura do medo e da intimidação espalha-se pelos espaços públicos das cidades, transformando-a sem cessar em áreas extremamente vigiadas, dia e noite.

A ideia de vigilância e controle do território e da população nos dá indícios da biopolítica que procura manter a lógica de purificação e controle do espaço urbano. Voltando na história, na Idade Media, era comum condenar doentes leprosos a se retirarem da cidade, a fim de manter certa purificação do espaço urbano. Leprosos eram vistos como pessoas não gratas no meio da cidade e que deveriam ser isoladas e afastadas a fim de que não contaminassem os cidadãos puros, como bem destaca Bauman (2009, p. 88):

$\mathrm{Na}$ idade média, o leproso era alguém que, logo descoberto, era expulso do espaço comum, posto fora 
dos muros da cidade, exilado em um lugar confuso onde ia misturar sua lepra com a lepra dos outros. O mecanismo de exclusão era o mecanismo do exílio, da purificação do espaço urbano.

$\mathrm{Na}$ atualidade, ao analisar a população da cidade, parece que alguns ainda são vistos e condenados como os leprosos de outros tempos. Muitos são excluídos pelo simples fato de serem moradores de uma determinada região, ou possuírem um determinado biotipo condenado pelas forças de segurança que mantêm a vigilância e o controle das cidades.

No caso específico de Três Barras, as falas dos entrevistados revelam que os moradores das regiões de São Cristóvão, João Paulo II, Diva Costa, Charqueada e Banhado são os que mais sofrem preconceitos, discriminação e têm sua imagem vinculada a aspectos negativos da cidade. Do mesmo modo, em Canoinhas percebe-se que os moradores das comunidades de Raia, Sangue Dois, Morro da Fumaça, Loteamento Santa Cruz sentem dificuldades similares aos das regiões citadas em Três Barras. Ser morador dessas regiões é estar em constante situação de suspeita, de vigilância, de controle, de afastamentos e de abandono.

As políticas públicas e os equipamentos construídos nas periferias da cidade são voltados para a reprodução e a sobrevivência da vida meramente biológica. Geralmente, os equipamentos públicos na periferia são: Escolas, Postos de Saúde, Centro de Atendimento Psicossocial, Centro de Referência em Assistência Social, Unidade Prisional Avançada. Enfim, políticas que reforçam mais os aspectos da Zoé, ou seja, a vida meramente biológica, ao invés de ampliar a construção de equipamentos para potenciar a Bios, a vida qualificada em seu âmbito público. Porque nesses espaços não são potencializados a vida qualificada, partícipe das decisões sobre os rumos da cidade?

Retomando novamente o pensamento de Agamben (2002), quando o filósofo afirma que o campo de concentração é manifestação biopolítica contemporânea, o paradigma político de nosso tempo, pode-se observar que, em determinadas áreas da cidade, ocorre a reprodução deste modelo. Observa-se a 
cultura do medo, a qual assola a cidade. O sistema de controle total é vivenciado nas cidades através de um sistema cada vez maior de vigilância 24 horas. Somente no centro da cidade de Canoinhas foram instaladas, até novembro de 2014, dez câmeras públicas de vigilância eletrônica. Além disso, existe um $s^{2} e^{5}$ que qualquer cidadão, em qualquer parte do mundo, pode acessar e ficar acompanhando, monitorando a movimentação em regiões das cidades vigiadas por câmeras que transmitem as imagens para serem acompanhadas em tempo real.

Voltando à experiência dos campos de concentração, percebe-se o quanto era rigoroso o controle das pessoas. Vistas o tempo todo como suspeitas, estigmatizadas e rotuladas como vidas que perderam o valor. Se no campo de concentração a biopolítica era visível e intensa, em alguns bairros e segmentos da população existentes hoje nas cidades nota-se que essa condição ainda está presente.

Ao referir-se à população de alguns bairros, é comum ouvir frases do tipo: "lá só tem bandido", "tinha que prender todo mundo", "esse povo não vale nada", "não adianta construir nada, pois eles só vão destruir", "tinha que fazer 'uma limpa", "tinha

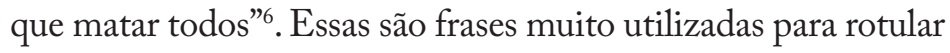
a população de alguns bairros, o que nos remete ao pensamento racial e biopolítico, característico dos regimes totalitários expressos nas ideias de Hitler, de Mussolini, de Stalin - que classificavam a população como os "puros" e os "impuros", os "bons" e os "maus". Os que poderiam viver e os que seriam condenados a morrer. Talvez a intensidade da biopolítica nas cidades se expresse de outras formas, cuja similaridade com um campo de concentração fique evidente. Contudo, a lógica que administra um território e uma população, a partir do exercício do poder do soberano (fazendo uns viverem enquanto outros são deixados para morrer) continua a mesma, na medida em que constituiu o fundamento da proposta civilizatória ocidental segundo Agamben (2002).

De outro modo, no aspecto de ágora pública a cidade é organizada de forma similar ao mundo grego antigo. Observa-se que, no centro da cidade, e em áreas consideradas nobres, existem sedes administrativas (prefeitura e outros
5 Consultar:

$<\mathrm{http} / / /$ www.sulaovivo.com.br/>.

6 As frases em destaque foram colhidas informalmente durante a pesquisa São trechos de diálogos com moradores de áreas nobres das cidades em questionamentos sobre o que eles pensavam a respeito da população residente em alguns bairros da periferia, tais como o bairro São Cristóvão (em Três Barras) e o da Raia (no Campo da Água Verde, em Canoinhas). 
órgãos), espaços para debates dos representantes do povo (câmara de vereadores), praças, cinemas, bancos, comércio, ruas asfaltadas, calçadas, arborizadas, saneamento básico; enfim, há um ambiente propício para que os cidadãos possam circular livremente, participar da vida da cidade e usufruir com tranquilidade dos seus vários benefícios. Situação contrária é encontrada em regiões periféricas, onde o abandono e a depreciação parecem ser o destino de seu ambiente.

Em vários aspectos das cidades, constatam-se as evidências biopolíticas do campo de concentração e o contraste com a ágora pública. Para um breve exercício comparativo, foi elaborado um quadro que representa como é a conformação do espaço citadino em uma cidade pensada na perspectiva de ágora pública e em uma cidade organizada no sentido de campo de concentração. Esse quadro foi elaborado com referência nas duas cidades estudadas.

Quadro 1 - O campo de concentração como paradigma dos espaços citadinos

\begin{tabular}{|c|c|c|}
\hline Aspecto & Cidade = ágora pública & $\begin{array}{l}\text { Cidade }=\text { campo de } \\
\text { concentração }\end{array}$ \\
\hline Cidadãos & $\begin{array}{l}\text { Respeitados, ocupantes } \\
\text { de cargos públicos, } \\
\text { destaques na sociedade, } \\
\text { circulam livremente. }\end{array}$ & $\begin{array}{l}\text { Suspeitos, rotulados, } \\
\text { vigiados, invisíveis, } \\
\text { vidas sem valor. }\end{array}$ \\
\hline Moradias & $\begin{array}{l}\text { Boas condições, bonitas, } \\
\text { grandes, confortáveis. }\end{array}$ & $\begin{array}{l}\text { Precárias, pequenas, } \\
\text { sem durabilidade. }\end{array}$ \\
\hline Ruas & $\begin{array}{c}\text { Asfaltadas, calçadas, } \\
\text { arborizadas, iluminadas. }\end{array}$ & $\begin{array}{l}\text { Sem pavimentação, sem } \\
\text { iluminação, estreitas. }\end{array}$ \\
\hline $\begin{array}{l}\text { Equipamentos } \\
\text { públicos }\end{array}$ & $\begin{array}{c}\text { Praças, bancos, unidades } \\
\text { administrativas, cinema, } \\
\text { comércio. }\end{array}$ & CRAS, UPA, CAPS... \\
\hline Prisão & $\begin{array}{l}\text { A prisão de um } \\
\text { morador do centro é } \\
\text { um escândalo, e esse } \\
\text { cidadão não fica preso } \\
\text { por muito tempo. }\end{array}$ & $\begin{array}{l}\text { A prisão de um morador } \\
\text { da periferia é destino } \\
\text { recorrente. E, quando é } \\
\text { preso, esse cidadão fica } \\
\text { grande parte de sua vida } \\
\text { nessa condição. }\end{array}$ \\
\hline $\begin{array}{l}\text { Emprego e } \\
\text { renda }\end{array}$ & $\begin{array}{c}\text { Melhores cargos } \\
\text { e salários, com } \\
\text { possibilidade de ter boas } \\
\text { condições de vida. }\end{array}$ & $\begin{array}{l}\text { Emprego informal, salário } \\
\text { baixo e renda insuficiente } \\
\text { para melhorar sua } \\
\text { qualidade de vida. }\end{array}$ \\
\hline
\end{tabular}

Fonte: Elaborado pelos autores. 


\section{Considerações finais: desenvolvimento para que e para quem?}

Pensar e planejar os espaços públicos, para atender aos mais variados setores e segmentos da sociedade, de forma que fosse possível uma convivência sociocomunitária foi e continua sendo o desafio para a administrabilidade do território e das pessoas que compõem uma cidade.

Pensar a cidade como ágora pública ou como campo de concentração pode levar para caminhos opostos à lógica do desenvolvimento local e regional, a partir da tomada de posição sobre um dos aspectos aqui apontados. Alguns desafios imediatos apresentam-se no sentido de questionar: como é possível pensar em desenvolvimento regional se as pessoas são tratadas de formas diferentes, ficam confinadas em algumas áreas e não podem usufruir livremente de todos os espaços das cidades? Para Bauman (2009, p. 69) “[...] um espaço é público à medida que permite o acesso de homens e mulheres sem que precisem ser previamente selecionados".

Se levarmos a perspectiva analítica de Bauman e, sobretudo, de Agamben adiante, pode-se afirmar que, pela lógica biopolítica que transforma as cidades em campos de concentração, não será possível existirem espaços públicos, pois não é permitido que a totalidade da população viva livremente. Moradores são selecionados, classificados, rotulados a partir de seus endereços e do biotipo que possuem, o que limita a sua circulação e os priva de obter benefícios da cidade propagada para todos.

Pensar o desenvolvimento regional é questionar o que, de fato, a cidade produz. A política não poderá produzir espaços públicos, se não for capaz de olhar seus habitantes como seres humanos para além de suas estruturas biológicas. Pedro Lucas Dulci (2014, p. 114-133), mestrando em Filosofia pela Universidade Federal de Goiás, fala que a condição humana é fundamental para a questão urbana: "Um conjunto de cidades que já não produz mais humanos, mas tão somente vidas que sobrevivem reduzidas à mera gestão de suas atividades biológicas, por definição, não são mais espaços políticos”. 
Utilizando o critério de vida qualificada em seu âmbito público, as cidades de Canoinhas e Três Barras são referências para esse tipo de desenvolvimento? Os espaços citadinos são conformados para o público? São pensados, planejados os espaços, as áreas e os equipamentos para que toda a população possa usufruí-los? Segundo Harvey (2003, p. 43), as cidades estão, cada vez mais, cercando os espaços públicos e os tornando áreas privatizadas: "Nossas cidades, cada vez mais consistem de fragmentos fortificados, condomínios fechados e espaços públicos privatizados, mantidos sob vigilância constante".

$\mathrm{Se}$ as cidades insistirem na ideia de fortificação, monitoramento, vigilância, separação da população entre os que podem viver e os que serão deixados para morrer, políticas que reproduzem as práticas de campo de concentração, dificilmente poderemos falar em desenvolvimento regional. Nesse modelo, a tendência é a cidade ser usada para aprisionar a vida ao invés de potencializá-la.

Sob pressupostos biopolíticos de Agamben, a cidade pode se apresentar como paradigma do campo de concentração, lugar para fazer viver ou fazer morrer. As questões que ficam são: sob quais fundamentos os administradores pensarão o desenvolvimento regional? O planejamento e a conformação dos espaços citadinos serão, cada vez mais, fortificados, eletrificados e cercados semelhantes aos campos de concentração ou o espaço será aberto para que seus habitantes possam participar, decidir e compartilhar todos os benefícios da vida qualificada em seu âmbito público?

\section{Referências}

AGAMBEN, Giorgio. A comunidade que vem. Tradução de António Guerreiro. Lisboa: Editorial Presença, 1993.

AGAMBEN, Giorgio. Homo Sacer: o poder soberano e a vida nua I. Tradução de Henrique Burigo. Belo Horizonte: Editora UFMG, 2002.

AGAMBEN, Giorgio. Estado de Exceção. Tradução de Iraci de Poleti. São Paulo: Boitempo, 2004. 
AGAMBEN, Giorgio. El Reino y la Gloria: Una genealogía teológica de la economía y del gobierno. Traducción de Flavia Costa, Edgardo Castro y Mercedes Ruvituso. Buenos Aires: Editora Adriana Hidalgo, 2008a (Homo Sacer, II, 2).

AGAMBEN, Giorgio. O que resta de Auschwitz: o arquivo e a testemunha (Homo Sacer III). Tradução Selvino José Assmann. São Paulo: Boitempo, 2008b.

AGAMBEN, Giorgio. O que é o contemporâneo e outros ensaios. Tradução de Vinicius Nicastro Honesko. Chapecó: Argos, 2009.

ARISTÓTELES. Política. Tradução de Mário da Gama Kury. Brasília: UnB, 1989.

BAUMAN, Zigmund. Modernidade Líquida. Rio de Janeiro: Jorge Zahar Ed., 2001.

BAUMAN, Zigmund. Confiança e Medo na Cidade. Rio de Janeiro: Jorge Zahar Ed., 2009.

DULCI, Pedro Lucas. A condição humana como condição urbana: por uma genealogia do antropólogo no político. Revista Profanações, ano 1, n. 2, p. 114-133, jul./dez. 2014.

FOUCAULT, Michel. História da sexualidade I: a vontade de saber. Tradução de Maria Thereza da Costa. Albuquerque e revisão de José Auguto Guilhon Albuquerque. Rio de Janeiro: Rio de Janeiro: Graal, 1998.

FOUCAULT,Michel. Em defesa da sociedade: curso no College de France. Tradução de Maria Ermantina Galvão. São Paulo: Martins Fontes, 1999.

FOUCAULT, Michel. Microfísica do Poder. Organizado por Roberto Machado. Editora Graal. 16. ed. Rio de Janeiro: Edições Graal, 2001.

FOUCAULT, Michel. Segurança, Território, População: curso dado no Collège de France (1977-1978). São Paulo: Martins Fontes, 2008.

GARCIAS, Carlos Mello; BERNARDI, Jorge Luiz. As Funções sociais da Cidade. Revista Direitos Fundamentais e Democracia, Curitiba, v. 4, p. 1-15, 2008.

HARVEY, David. O direito a cidade. Revista Piauí, São Paulo, n. 82, p. 38-43, jul. 2013.

INSTITUTO BRASILEIRO DE GEOGRAFIA E ESTATÍSTICA. Censo 2010. Disponível em: <http://www. censo2010.ibge.gov.br>. Acesso em: 10 maio 2016. 
SOUZA, Marcelo Lopes de. ABC do desenvolvimento urbano. 6. ed. Rio de Janeiro: Bertrand Brasil, 2001.

SUL AO VIVO. 2016. Disponível em: <http://www.sulaovivo.com. br/>. Acesso em: 5 maio 2016.

Submetido em: 27/12/2015

Aprovado em: 29/08/2016

\title{
THE BIOPOLITICS DEMONSTRATIONS IN THE CONFORMATION OF CITY SPACES OF THE NORTH PLATEAUOF SANTA CATARINA AND ITS IMPLICATIONS ON REGIONAL DEVELOPMENT
}

\begin{abstract}
This article is the result of the research project: "The relationship biopolitics in the conformation of city spaces of the North Plateau of Santa Catarina and its implications on regional development", developed between the years 2013 and 2014 at the University of Contestado. Through this project we sought to understand the dynamics biopolitics governing the organization of cities, in the conformation of city and urban spaces where people move, or that should be circumscribed, in order to check the effectiveness manageability of life and death of such citizens. From the theoretical and conceptual assumptions arising from the political and legal philosophy of the Italian philosopher Giorgio Agamben, the city can be presented and analyzed as political paradigm of contemporaneity, which is expressed in the concentration camp, where it enhances the living and, manages the die.
\end{abstract}

Keywords: Cities. Biopolitics. Lifetime. Death. 